Quantitative Political Economy Research Group

Department of Political Economy

King's College London

\title{
QPE
}

\section{Selectively liberal? Socio-economic change and attitudes towards homosexual relations}

QPE Working Paper 2020-9

Alan Collins

Stephen Drinkwater

Colin Jennings

June 16, 2020 


\title{
Selectively Liberal? Socio-Economic Change and Attitudes Towards
}

\section{Homosexual Relations}

\author{
Alan Collins \\ Nottingham Trent University \\ Stephen Drinkwater \\ University of Roehampton, London \\ Colin Jennings \\ Kings College London
}

\begin{abstract}
This paper focuses on two important social phenomena that have pervaded across Western countries over the last 50 years - a general liberalisation in attitudes towards LGBT people and an increase in multiculturalism. We investigate the links between these two social processes by focusing on changes in attitudes with regards to homosexual relations in Great Britain. We show that the British population displays considerably more tolerant views towards homosexuality compared to the end of the 1980s. However, there is evidence that this has slowed over recent years, especially in areas that have experienced the highest levels of immigration, particularly from countries outside Europe. We explain these changes with reference to two effects that immigration may have - direct cultural and indirect political effects - the latter manifested in selective liberalisation. We explore both influences using survey data and find strong evidence for the first effect and suggestive support for the second effect.
\end{abstract}




\section{Introduction}

Recent decades have witnessed a dramatic change in social attitudes towards homosexual relations across the globe. The UK, which provides the focus of this paper, is no exception. However, casual observation is sufficient to tell us that this change has not been uniform across all groups. Many groups that identify by religion are shown to hold more intolerant views towards the Lesbian, Gay, Bisexual and Transgender (LGBT) population (Brittain and McKinnon, 2011). In the UK, liberalisation of attitudes has occurred more rapidly amongst the white population than amongst ethnic minorities (Collins and Drinkwater, 2017).

We provide a detailed focus on whether significant changes in attitudes towards homosexual relations extend to other social attitudes. In particular, is liberalisation on this dimension, part of a package of liberalisation that extends to a range of attitudes? If this is the case, one might expect a more liberal attitude on matters of sexuality to be combined with more liberal attitudes in a dimension such as law and order, reflected in the expression of relatively more libertarian than authoritarian attitudes. However, in contrast to a package of general liberalisation, it may be that liberal expression is selective. It may be the case that for a significant proportion of the white population in the UK that liberalisation in their attitudes is itself a conflicting response to attitudes held by ethnic minorities ${ }^{1}$. These may be particularly related to those attitudes held by the Muslim population, which in recent times has become the salient 'out-group' ${ }^{2}$ within western societies (see, for example, Modood, 2005; Poynting and Mason, 2006; Abbas, 2007; Betz, 2016; Ragazzi, 2016; Narkowicz and Pędziwiatr, 2017). This suggests that some of the liberalisation in attitudes towards the LGBT population may be strategic.

There has been a massive shift in attitudes towards homosexuality across a range of countries over the past fifty years, especially in the past couple of decades. This has been reflected in both responses to surveys as well as recent changes in legislation such as the legalization of gay marriages in the US and UK and a majority vote in

\footnotetext{
${ }^{1}$ This relates to perceptions of various aspects of ethnic identity including 'openness to majority social norms'. This has been empirically explored from a labour market perspective by Gorinas (2014).

${ }^{2}$ For a detailed early social psychological analysis of the formation, composition and nature of ingroups and out-groups see Allport (1954).
} 
favour in Ireland in 2015. The last 50 years have heralded in a number of changes in legislation towards LGBT people in the UK, which has been accompanied by a change in social attitudes - although not always in a progressive/positive direction. Legislatively, this social change started with the partial decriminalization of homosexuality in 1967 (but not until the 1980s in Scotland and Northern Ireland). However, progress stalled in the 1980s, mainly because of increased homophobia in the UK in the early 1980s and the introduction of Section 28 (Cameron et al, 2009). Change then again started to occur in the 1990s, with the age of consent reduced to 18 (rather than 16) in 1994 and the New Labour pledge in 1997 to remove all discrimination against LGBT people. This continued into the 2000s with a long list of individual rights enhancements. This included, inter alia, the removal of the ban on gay men and lesbians by the armed forces in 2000; equalization of the age of consent in 2001; gay couples and singles being able to apply to adopt children in England and Wales from 2002 (and in Scotland in 2009); repeal of the infamous 'Section 28' of the Local Government Act in 2003; introduction of 'Civil Partnerships' in 2004 and, most recently, the introduction of same-sex marriages in 2014 (but not as yet in Northern Ireland (NI) - though the UK Parliament in the absence of a Stormont working Government has progressed legalization such that the first NI same sex marriage was in February 2020). ${ }^{3}$

Beyond the statutory context, 'Pride' festivals have been established and evolved across UK cities (as well as elsewhere across the world). The first official UK Gay Pride Rally was then held in London in 1972, followed by Brighton Pride the next year and then Manchester Pride in 1986. These were initially restricted to the biggest urban centres but now also take place in a wide range of cities. This indicates that an increasing tolerance towards LGBT people has permeated out from those areas that have traditionally been most accepting of people with different sexual orientations. At the same time as these changes occurred, rising levels of immigration, especially into the most heavily populated parts of the largest cities - particularly London - may have had the effect of slowing down levels of tolerance towards homosexual relations, even though all areas have become more tolerant. Net migration for the UK was negative until the 1980s and has been largely positive ever since, especially since the early

\footnotetext{
${ }^{3}$ Further details on some of these developments can be found in this BBC online article: http://www.bbc.co.uk/news/uk-40743946
} 
1990 's since when it has been at historically high levels reaching more than 300,000 before the 2016 referendum on UK membership of the European Union (White, 2018). The highest levels of immigration have been observed in London, its surrounding areas and to other big cities. ${ }^{4}$

To examine how relevant attitudes have evolved, this study uses data from the British Social Attitudes Survey (BSAS) to look at changes over a relatively long time period, starting in the early 1980s. This was a time in which there were typically very intolerant attitudes towards homosexuality, with well over a half of adults $(56 \%$ in 1989 ) reporting that they thought that this was always wrong in the late 1980s. Since then public attitudes have changed considerably, with this percentage falling to $15 \%$ in 2015. This is similar to the evidence presented by Loftus (2001) for the United States between 1973 and 1998. In our analysis, we pool consecutive cross-sectional datasets to examine how attitudes have changed across different demographic groups, thereby identifying the factors that have contributed most to the liberalisation of attitudes and other observed changes.

Moreover, a notable feature of our paper is a focus on the possibility that some of the liberalisation in attitudes may be strategic as a conflicting response to perceived outgroups, most notably Muslims. While a direct test of this is difficult, more indirect tests can shed some light on this possibility. In particular, we provide a comparison with attitudes towards pre-marital sex and stiffer sentences and can again contrast the attitudes of the white majority to those of Muslims and other minority groups. Attitudes on pre-marital sex provide results that are similar to attitudes towards homosexual relations. Immigrants and minorities tend to have much less liberal attitudes, and as a result London appears as the least liberal region in the UK. The key difference with homosexual relations is that the regions outside London in the 1980s did not have views that especially differed from those in London. It seems that all the change has been driven by the increased proportion of ethnic minorities and not by significant changes in attitudes in the white population. We can speculate that one possible key difference compared with attitudes to homosexual relations is that pre-

\footnotetext{
${ }^{4}$ Further details on flows of migrants to the UK as well as on stocks of migrants are provided in the online appendix.
} 
marital sex is not associated with a clearly identifiable out-group. In the 1980s the LGBT community provided an out-group at a time when the immigrant population was relatively small. This contributes to homophobic attitudes. But as immigration increased and the Muslim population becomes the main out-group, attitudes have shifted towards increased tolerance towards the LGBT population as a strategic shift from one targetable out-group to a new targetable out-group. ${ }^{5}$ Pre-marital sex provides no such target. An area where there are often perceived to be differences between more conservative communities and more liberal ones is over law and order. This is borne out in attitudes to stiffer sentences. A second implication is that there would be little strategic incentive to alter attitudes if the Muslim community does not express especially strong views. There is little value in altering an attitude if is not perceived as imposing a cost upon the salient out-group.

Our paper is not focused on party politics, but it does tap into a literature that has developed around the changing focus in the politics of the radical right in Britain and the wider world over the last two decades (Jennings and Ralph-Morrow, 2020). A distinguishing feature of how radical right politics has altered stemming back to the emergence of Pim Fortyn in the Netherlands at the turn of the century is a more narrow focus on Muslims as a target and as a corollary how they pose a threat to liberal values concerning gender and LGBT rights (Akkerman, 2005). This approach spread to the 'detoxification' in France of the National Front (Almeida, 2017) and more generally as indicated by Eatwell and Goodwin (2018) in their study of national populism. Meadowcroft and Morrow (2017) show how acceptance of LGBT rights has even extended to the far-right English Defence League founded by Tommy Robinson. A key distinction, however, between the discussions of LGBT rights in radical-right politics and mainstream politics is that the former only tend to discuss it with reference to the alleged homophobic attitudes of Muslims and not as an isolated issue in itself. Indeed, as Eatwell and Goodwin (2018) argue, a reason why national populists are able to tap into support that traditionally was given to the Democrats in the USA and the Labour party in the UK is that these parties are perceived as now

\footnotetext{
${ }^{5}$ The implication is that the sincerity of the expression of an attitude should be subject to interrogation, As an example, Giani and Meon (forthcoming) show that reported racial bias in the European Social Survey increased within an interval of \pm 15 days around the election of Donald Trump and the effect then vanished, The authors do not interpret this as a change in preferences, which in turn implies that respondents in surveys may often suppress their true attitudes on race.
} 
focusing too much on issues such as LGBT rights! In these latter cases, LGBT rights are, of course, discussed commonly without reference to Muslims. So the expression of support for the gay population may, amongst some groups, be conditional on being couched in terms that draw attention to their concern with Muslims. This paper aims to theoretically and empirically tease out some of this distinction between increased acceptance of gay rights in and of itself and where it has increased as a response to what are perceived to be Muslim homophobic attitudes, as a means by which Muslims can be attacked as not sharing British values. This of course begs the question as to whether expressions of tolerance towards the gay population are sincere or strategic.

The next section sets out a theoretical enquiry into this problem, which is used to establish the two main hypotheses that steer the subsequent empirical phase of the study. The following sections then provide details on the data used and the multivariate analysis deployed to explore those hypotheses, with the findings discussed therein. A final section offers a summary of the main findings and key conclusions.

\section{Theoretical Background}

The discussion is based around two effects of immigration on attitudes towards homosexual groups. The first is a direct effect, whereby the arrival of migrants from different parts of the world, especially into London, has changed the relative spatial balance of attitudes, given that certain migrant groups have more conservative attitudes. Religion is important here especially with regards to Muslims. ${ }^{6}$ The indirect effect refers to the indigenous population with traditional (authoritarian) attitudes, who may have become more tolerant towards certain groups such as homosexuals because these groups are (even) less popular with groups of Muslim immigrants. In this section, we develop theoretical insight into the indirect effect. ${ }^{7}$

We present a simple depiction of the problem for a member of group A (the in-group) that experiences disutility from increasing utility for members of group B and C (the

\footnotetext{
${ }^{7}$ The indirect effect is similar to the mechanism explored in Glaeser (2005) where voters sometimes support policies that would appear to hurt them, but do so because they believe that they are more than compensated by the pain it inflicts on the group that they perceive to be their enemy.
} 
out-groups). Group B may be thought of as the LGBT population and Group C as the Muslim population. Group A members can undertake actions or form attitudes targeting the other groups that reduce the utility of $\mathrm{B}$ and $\mathrm{C}$ and as a result increase the utility of group A. We label these actions $X_{A(B)}$ and $X_{A(C)}$, where the subscripts denote actions taken by group A against the bracketed group. These actions are taken with costs $c\left(X_{A(B)}\right)$ and $c\left(X_{A(C)}\right)$. We assume that group $\mathrm{C}$ also derives utility from the disutility of group B. $T_{B}$ and $T_{C}$ denote the perceived threat that groups B and C pose to the values of group A. This may be related to the size of the groups, but would also relate to actions taken by a subset of members of group $\mathrm{B}$ and $\mathrm{C}$ which are directly threatening to group A, such as terror attacks. This leads to the following utility function for a member of group A.

$$
U_{A}=U_{A}\left(T_{B} U_{B}\left(X_{A(B)}\right), T_{C} U_{C}\left(X_{A(C),} U_{B}\left(X_{A(B)}\right)\right)\right)
$$

maximising with respect to $X_{A(B)}$ and $X_{A(C)}$ gives

$$
\begin{gathered}
T_{B} \frac{\partial U_{A}}{\partial U_{B}} \frac{\partial U_{B}}{\partial X_{A(B)}}+T_{C} \frac{\partial U_{A}}{\partial U_{C}} \frac{\partial U_{C}}{\partial U_{B}} \frac{\partial U_{B}}{\partial X_{A(B)}}=c^{\prime}\left(X_{A(B)}\right) \\
T_{C} \frac{\partial U_{A}}{\partial U_{C}} \frac{\partial U_{C}}{\partial X_{A(C)}}=c^{\prime}\left(X_{A(C)}\right)
\end{gathered}
$$

Begin by supposing a society where intolerance of groups $\mathrm{B}$ and $\mathrm{C}$ is widely held within large swathes of the population. There would be little social stigma attached to engaging in negative actions and language aimed at both groups. This would be reflected in low values of $c^{\prime}\left(X_{A(B)}\right)$ and $c^{\prime}\left(X_{A(C)}\right)$. Nonetheless, there is a further cost for members of group A in taking actions against group B, which is that the second term in (2) tells us that these actions increase the utility of group $\mathrm{C}$, which in turn reduces the utility of group A. However, supposing that the threat $T_{B}$ is perceived as relatively large, the negative effect of benefitting group $\mathrm{C}$ may not have much importance. So actions and language may be used against the LGBT and Muslim communities, because any contradicting indirect effect that may exist in such actions may be swamped by the benefits of directly hurting each group.

Now suppose two changes occur. First, social stigma against all forms of intolerance increases, but this is particularly the case for intolerance of liberal rights such as those for the LGBT population, which are here depicted as group B. In this case both marginal costs would rise, but $c^{\prime}\left(X_{A(B)}\right)$ would increase more than $c^{\prime}\left(X_{A(C)}\right)$. If this 
was the only change then intolerance would be reduced towards both groups. However, the second change may counteract this at least to some extent. That is, due to an increase in the size of group $\mathrm{C}$ or extremist actions taken by some of its members, $T_{C}$ increases. The result of this is twofold. First, it further reduces the benefit of hostile actions and language against group B because the second term in (2) becomes even more negative and thus further reduces the benefit of intolerance towards group B. Second, because $T_{C}$ increases the benefit of intolerance in (3) increases.

The key points to take from the simple theoretical approach depicted here for the empirical analysis is as follows. We can think in a highly stylistic manner of the indigenous population as composed of those in a metropolitan city and those outside. For example, in London in the 1980s attitudes to homosexual relations were already liberal. Attitudes to immigrants were also liberal. Clearly these attitudes may have been held with conviction. Alternatively, they could have been driven by costs and benefits. The stigma costs of expressing intolerance towards any out-group were very high. In addition, for the liberal representative of a metropolitan city neither outgroups would have been perceived as a threat. That is $T_{B}=T_{C}=0$. In this case liberal attitudes towards all out-groups are expressed and this does not change across the sample period of data from the 1980s to the present day.

Alternatively, we can construct a stylized set of preferences for an indigenous representative outside a metropolitan area or large provincial city. In the 1980s stigma costs may have been low and both out-groups are considered threatening. However, given the low salience of Muslims $T_{B}$ is more prominent than $T_{C}$. This would lead to the expression of attitudes that are intolerant of homosexual relations. Over the next three decades, social change results in stigma costs increasing especially with regards to homophobic sentiment. In addition, the Muslim population becomes a larger perceived threat ${ }^{8}$. In (2) we can see that if $T_{B}$ is falling and $T_{C}$ and $c^{\prime}\left(X_{A(B)}\right)$ are rising this would lead to more tolerant expression of attitudes with regard to homosexual relations. However, this may happen as a strategic response to changes in perceived threat and social stigma unrelated to fundamental shifts in underlying

\footnotetext{
${ }^{8}$ Fielding (2018) takes a long-term perspective when examining tolerance in relation to regional variations in attitudes towards a specific ethnic group.
} 
attitudes themselves. While, we would agree that there has clearly been an increase in tolerance towards the LGBT population which is independent of any other factors, we do think for a potentially significant number of the indigenous population the expression of attitudinal change has been driven to some extent by strategic considerations. That is, expression of tolerance towards the LGBT population may be perceived to impose costs upon the immigrant population. This extra dimension would accelerate the already increasing tolerance of homosexual relations, especially as immigration became a more salient issue in the $21^{\text {st }}$ century.

In the other attitudes we analyze (pre-marital sex and the death penalty) the bolstering effect identified for homosexual relations would not apply because there is not an identifiable threatening out-group strongly in favour of pre-marital sex with which the Muslim population is perceived to be in strong disagreement with. So although supporting pre-marital sex would run contrary to Muslim opinion, it would not also lead to more liberal attitudes towards an identifiable group associated with pre-marital sex because no such group really exists. The absence of a contrasting identifiable outgroup also applies in attitudes towards the death penalty. In addition, although Muslims are relatively more in favour of it than the hypothetical indigenous Londoner, the preference is not strong and there may be perceived to be little advantage for the hypothetical indigenous non-Londoner in softening their position as it will do little to hurt the Muslim population that they perceive as a threat. These factors may help to explain why the liberalisation that has been witnessed in attitudes towards homosexual relations has not simply been reflective of a wider set of liberalisation across a large range of attitudes. While London may be the least liberal region in the UK in terms of attitudes on homosexual relations, it is still the most liberal on other matters and the identifiable nature of the LGBT population and the strategic considerations discussed here may be relevant to that contradiction.

This theoretical enquiry may be distilled into two key sequentially more focused hypotheses to guide the empirical phase of the study:

Hypothesis 1: UK ethno-religious immigrant out-groups present greater conservatism in social attitudes to the existence and/or conduct of individual rights labelled outgroups, such as the LGBT population. 
Examination of this hypothesis helps establish a case for claiming the presence of disutility among ethno-religious immigrant out-groups deriving from the presence and activities of the LGBT population. It also highlights the potential utility to the ingroup derivable from an awareness that this ethno-religious immigrant out-group disutility exists.

Hypothesis 2: Higher levels of immigration lead to a higher degree of selectively liberal expression by the in-group (primarily comprising the white majority population) in their attitudes to socially conservative ethno-religious immigrantlabelled out-groups. This in-group selectivity is framed in relation to an individual rights-based (i.e. not ethno-religiously denominated) out-group such as that comprising the LGBT population.

\section{Data}

The data used in this paper are taken from the BSAS, which is a representative sample survey of respondents living in Great Britain. There is a separate study in Northern Ireland. The data that we use covers the period from 1983 to 2015 and has been used over a long period to examine a wide range of issues by social science researchers such as Blanchflower (1991), Chan and Goldthorpe (2007) and Grasso et al. (2019). A consistent question on attitudes towards homosexual relations has been asked in many of the years that the survey was undertaken. However, there are some years that it didn't feature and the BSAS did not take place in 1988 and 1992. Therefore, we have data for 1983-5, 1987, 1989, 1990, 1993, 1995, 1998-2000, 2003, 2005-7, 2010, 2012, 2013 and 2015. Responses to the question on homosexual relations have previously been analysed by other authors including Collins and Drinkwater (2017). They note that although there has been a general liberalization in attitudes towards homosexuality across Britain (establishing Hypothesis 1), this has not been evenly distributed in different parts of the country, including variations between urban and rural areas.

There are some particulars relating to the BSAS data including that some questions are only asked in certain years. This is partly why the data needs to be appropriately 
grouped across years, rather than being able to examine each year separately because the temporal trends are smoothed with a larger number of observations. These features are shown in Table 1, which shows how attitudes towards homosexual relations have evolved in Britain in since the early 1980s. The data have been split into four time periods that essentially reflect the decades: 1983-89, 1990-99, 2000-9 and 2010-15. As a result, Table 1 clearly shows that such attitudes have become considerably more tolerant across the whole of Britain since the 1980s. More specifically, $56.2 \%$ of the British population thought that homosexual relations were always wrong in the first period (1983-89) compared to $17.6 \%$ in the final period (2010-15). Attitudes towards homosexual relations have liberalised more quickly for whites in comparison to ethnic minorities, with the mean level of homosexual relations reported by white respondents reporting falling from 3.98 to 2.25 between the first and fourth periods, compared with from 4.36 to 3.36 for ethnic minorities. It also shows the attitudes by region, with some distinct changes being observable over time. In particular, London begins as being by far the most liberal region with regards to attitudes towards homosexual relations (a mean of 3.66 in the first period compared to a mean of 3.93 in the next closest region - the South East) but by the final period London is the least tolerant region in this regard (a mean of 2.49 compared to 2.36 in the next closest region - the Midlands). This is an issue that we will focus on in some detail in the regression analysis that follows.

\section{Multivariate Modelling Approach}

The regression analysis is based around the following basic model using data from the BSAS:

$$
y_{i}=\alpha+X_{i} \boldsymbol{\beta}+\epsilon_{i}
$$

where $y_{i}$ represents the respondent's response to the question about their attitude towards homosexual relations (with a lower value indicating more liberal views), $\alpha$ a constant term, $X_{i}$ a vector of control variables (mainly standard socio-demographic characteristics and a constant term), $\boldsymbol{\beta}$ the associated vector of coefficients to be estimated and $\epsilon_{i}$ an error term. Four empirical specifications have been estimated, with the explanatory variables similar to those that have been included in the models estimated by Loftus (2001) and Andersen and Fetner (2008). Given the ordered nature 
of the dependent variable, ordered probit models have mainly been estimated. However, Ordinary Least Squares (OLS) models have also been estimated, for comparison purposes and ease of interpretation. These models tend to produce similar results, from a qualitative perspective, as well as generally in relation to significance of individual coefficients. This can be observed by comparing the OLS estimates with the ordered probit estimates in from Table A1. Differences in estimates with regards to key variables of interest are, however, noted.

In order to further examine the direct effect of the higher levels of immigration in London on relative changes in regional attitudes towards homosexual relations, the gap between attitudes towards homosexual relations in London and other parts of Britain is decomposed into two components using a regression-based technique initially developed by Oaxaca (1973) and Blinder (1973). The two components are an explained or characteristic effect and an unexplained or coefficients effect. ${ }^{9}$ The characteristic effect relates to the compositional differences between the samples in the two areas that are being compared. The unexplained component represents the part of the differential between the areas that cannot be explained by the variables that have been included in the regression model. This approach has been used extensively in the labour economics literature, especially in connection to wage differentials, where the unexplained component is often used to measure the extent of discrimination against a particular group. ${ }^{10}$ However, it will also include the effects of group differences in unobserved factors (Jann, 2008). The basic decomposition framework is:

$$
\bar{y}_{N L}-\bar{y}_{L}=\left(\bar{X}_{N L}-\bar{X}_{L}\right) \widehat{\boldsymbol{\beta}}+\bar{X}\left(\widehat{\boldsymbol{\beta}}_{N L}-\widehat{\boldsymbol{\beta}}_{L}\right)
$$

where the L subscript refers to residents living in London and the NL subscript to residents living in the rest of the UK. The bars represent average levels within the relevant samples and the hats the estimated coefficients from a pooled regression model. The importance of individual or different sets of characteristics can be quantified thought the application of a detailed decomposition (Jann, 2008). The

\footnotetext{
${ }^{9}$ There is a fairly large literature on the index number problem and the appropriate way to weight the coefficients in decompositions. Oaxaca and Ransom (1994) provide a detailed discussion on this matter. The decompositions in this study are based on the estimated coefficients from pooled regression models containing the samples for London and the rest of Britain, based on the routine outlined by Jann (2008).

${ }^{10}$ This approach has also been widely applied in a range of other contexts, including Jürges (2007), Jepsen and Jepsen (2009) and Ueffing et al. (2015).
} 
pooled models are estimated using OLS because of the number of challenges when applying detailed decompositions with non-linear models (Fortin et al., 2011).

In order to ascertain whether there has been a selective liberalism effect in relation to attitudes towards homosexual relations is provided through extending the basic regression model (4) to include some interaction terms:

$$
y_{i c}=\alpha+\sum_{j=1}^{4} \delta_{j} P_{j i}+\sum_{j=1}^{4} \sum_{k=1}^{3} \phi_{j k}\left(P_{j} \times E_{k}\right)_{i}+X_{i} \boldsymbol{\beta}+\epsilon_{i c}
$$

where these terms relate to interacting three decade/time period dummies $\left(P_{j}\right)$, which are measured relative to the reference period of 1983-89, with two educational dummies $\left(E_{k}\right)$ that have been measured relative to individuals in the highest qualifications category. These interaction terms will then measure how the attitudes of those with lower levels of education have changed over time in relation to highly educated people after controlling for other covariates. This model has only been estimated for Whites, given the focus on selective attitudes in connection to the impact of immigration and multiculturalism. The dependent variable also relates to attitudes towards pre-marital and stiffer sentences, as indicated by the c subscript, in order to compare these attitudes with those towards homosexual relations.

A second set of models that interact time and education have been also estimated using different measures of these effects. In particular, in (6) the time dummies have been replaced by a time trend $(T)$ and the levels of education by six highest educational qualification dummies $\left(Q_{i}\right)$ measured relative to degree:

$$
y_{i c}=\alpha+\tau T+\sum_{m=1}^{7} \theta_{m} Q_{m i}+\delta\left(T \times Q_{m}\right)_{i}+X_{i} \boldsymbol{\beta}+\epsilon_{i c}
$$

This has been done to more precisely estimate the impact of these variables, especially in more recent years. Given the rise in immigration following the election of the Labour Government, the analysis is based on data from 1997 to 2015 . This is because not only has this period seen a fairly rapid increase in immigration to Britain, it has also been accompanied by a rise in anti-immigrant opinions. In particular, English (2019) constructs a measure based on 111 items from 21 individual series 
over 26 years to show that public hostility towards immigration rose more or less continuously in Great Britain from the mid-1990s until $2015 .^{11}$

\section{Results}

An initial indication of the impact that immigration/multiculturalism may have had on changes in attitudes towards homosexual relations is provided by Table 2 . The estimates for the time-period dummies clearly confirm the large overall shift in attitudes towards homosexual relations becoming far more liberal in Great Britain since 1983, even after controlling for a range of socio-economic variables. In particular, the coefficients and significance levels on the time-period dummies do not vary substantially as additional covariates are included across the four specifications.

The table also shows the importance of ethnicity as indicated by the large and significant coefficient attached to the ethnic minority dummy in each specification. ${ }^{12}$ The magnitude of the coefficients does vary, particularly when controls for religious group are included in the final specification, thereby lowering the coefficient attached to belonging to an ethnic minority group. Table A1 provides further detail by highlighting on the impact of religion. In particular, individuals reporting that they are affiliated to each of the religious groups, apart from the Other Religion category, are significantly (at the $1 \%$ level or better) more likely to indicate a less liberal view towards homosexual relations compared to people with no religion. This is especially noticeable for Muslims, who display by far the most intolerant views towards homosexual relations.

From a regional perspective the table shows that respondents from London displayed significantly more liberal attitudes towards homosexual relations compared to some other regions over the whole period even after controlling for a range of sociodemographic controls had been included. The significance levels compared to other regions do however vary as more characteristics are included, especially education

\footnotetext{
${ }^{11}$ English (2019) also reports the measure for regions but the trends are not so clear, possibly because some of the items will be based on relatively small samples, especially for certain regions.

${ }^{12}$ A single ethnic minority dummy has been included because of changes in the ethnic group question asked in the BSAS over time. However, the inclusion of religious controls also means that the main cultural differences between ethnic groups can be captured, especially given the relationship between ethnic and religious groups in the UK.
} 
and religious group. For example, the difference between Scotland compared to London is not significant at the $5 \%$ in the final specification. ${ }^{13}$ The table also indicates the very strong influence of education on attitudes towards homosexual relations, which is lessened after controlling for age. Females also display a significantly more tolerant view towards heterosexual relations.

The results from decomposing the differences in attitudes towards homosexual relations between London and the rest of Britain are shown in Table 3. The mean differential shows how the gap in these attitudes has evolved over time, shifting from a large positive differential of 0.37 in the first period (indicating, on average, far more liberal views towards homosexual relations in London) to a large negative differential of -0.26 in the fourth period (far more conservative attitudes on average). Moreover, the characteristics effect could only explain less than $20 \%$ of the total mean differential in the first period but more than $70 \%$ of the differential in the fourth period. Further decomposing the characteristics effect indicates that the majority is accounted for by the different ethno-religious composition of London compared with the rest of Britain (further supporting Hypothesis 1). This is particularly apparent in the final period, where the contribution of the ethno-religious variables far exceeds the overall characteristics effect $(-0.39$ compared to +0.19$)$, given that the impact of these variables is partially offset by other socio-demographic factors. In particular, the London population continues to be relatively younger and have higher levels of education, both of which are associated with more tolerant attitudes towards homosexual relations.

The results for attitudes towards pre-marital sex have a similar pattern to those for homosexual relations. In particular, attitudes towards pre-marital sex have liberalised at a faster rate in other parts of Britain in comparison to London. A large negative differential is again apparent by the fourth period and this is almost entirely accounted for by the characteristics effect, especially the ethno-religious controls. Interestingly, the effects of the religious group dummies are relatively more important in

\footnotetext{
${ }^{13}$ As noted earlier, there has however been a change in the regional rankings with regards to attitudes towards homosexual relations over time, with London moving from the most to least liberal region in this regard over the past three decades. This is largely due to the increased levels of immigration and multiculturalism in London (Collins and Drinkwater, 2017).
} 
comparison to those in results for homosexual relations. ${ }^{14}$ However, the results for the law and order variable are quite different. Attitudes in London start as more liberal than in other parts of Britain and this gap widens slightly over time. This suggests that the adoption of liberal attitudes in matters of sexuality has not extended to other issues such as stiffer sentencing. Moreover, the coefficients effect accounts for the majority of overall differential in the final period, with the ethnic and religious controls contributing relatively little to the characteristics. This is particularly the case for the religious dummies but the effect of the ethnic minority dummy does increase over time.

An initial indication of whether there has been an increase in selectively liberal expression in the context of attitudes towards homosexual relations is provided by Table 4. This table reports the results from estimating (6). ${ }^{15}$ The only significant effect with regards to the interaction terms belongs to White people with the lowest levels of education in the most recent time period, which has a negative coefficient that is statistically significant at the $1 \%$ level. ${ }^{16}$ This suggests that the least educated section of the majority white population reported the biggest (most liberal) change in relation to attitudes towards homosexual relations in the period when immigration had reached its highest levels - both in relation to its magnitude and as a political issue in the UK. The interaction term between the medium education and final period dummies is also negative (indicating attitudes have also become more liberal in relation to more highly educated people) but not statistically different from zero. In contrast, there is a positive but insignificant interaction for this group with regards to attitudes towards pre-marital sex and no significant effects for stiffer sentences.

The estimates reported in Table 5 essentially show similar pattern based on interacting highest qualifications with a time trend over a shorter period. There is a statistically significant negative coefficient attached to the interaction between the time trend and the no qualifications dummy relative to graduates and those with $\mathrm{O}$ levels or

\footnotetext{
${ }^{14}$ Attitudes towards pre-marital sex were very similar in London and the rest of Britain, which contrasts with those for homosexual relations.

${ }^{15}$ There is no consistent question on attitudes towards immigrants in the BSAS over the periods of time that we are examining that would potentially enable a more direct test of the selective liberalisation effect that has been outlined.

${ }^{16}$ A very similar result is obtained if the model is estimated using OLS, where the coefficient is -0.237 and with a slightly smaller p-value (0.001 compared to 0.004$)$.
} 
equivalent at the $5 \%$ level. ${ }^{17}$ This again suggests that the liberalisation of attitudes towards homosexual relations is highest amongst the least educated individuals over the period when immigration levels and anti-immigrant sentiment were rising. In contrast, the interaction terms in the pre-marital sex and stiffer sentences models are positive and sometimes significant.

It could be argued that the selective liberalisation that has been identified may be due to those with low levels of education 'catching up' with more educated groups. However, there are a couple of reasons why this potential criticism can be refuted. Firstly, Table 6 reveals that over the whole period the lowest reduction in the mean level of attitudes towards homosexual relations was observed for the least educated group (those leaving school at 15) but there was a relatively high fall in the final period for this group - and especially people who left school at 16 - when levels and concerns about immigration peaked. Secondly, our findings are consistent with empirical studies that have identified the key factors in explaining the decision to exit the EU following the 2016 referendum. In particular, not only were older and less educated highly concentrated amongst leave voters but this group also reported relatively high levels of English nationalism and strong negative attitudes towards migrants (Clarke et al. 2017; Goodwin and Milazzo, 2017).

\section{Concluding Remarks}

This study has examined the relationship between increased levels of multiculturalism, due to inward migration, and attitudes towards primarily homosexual attitudes. In order to explore the phenomenon of selectively liberal expression we have also contrasted attitudes to homosexuality with those towards premarital sex and stiffer sentences. We highlight the direct effect from the arrival of immigrants (and their offspring) who generally have less liberal attitudes compared to the indigenous population, especially regarding attitudes towards homosexual relations. We also explore an indirect effect, whereby the white majority may have

\footnotetext{
${ }^{17}$ This significant finding is again slightly stronger in the OLS model, especially for the interaction between no qualifications and the time trend, which has the largest coefficient of all of the interaction terms and a p-value of 0.000 .
} 
changed their attitudes towards particular groups because there may be other groups of whom they hold in greater distaste.

We therefore provide evidence indicating a specific type of selectively liberal expression. That is, in addition to culturally changing attitudes, there is also a strategic component of selecting liberal attitudes in those matters for which the conservative attitudes of immigrants/minorities are strongest and thus adopting a more liberal position will cause immigrants/minorities (especially certain groups such as Muslims) more harm. In particular, we provide statistical evidence that this is likely to have played an important role in the considerable liberalisation of attitudes towards homosexual relations that have been observed in Great Britain over recent decades. This is most noticeable for certain groups - especially whites with low levels of education and when immigration rose after 1997.

Moreover, there appears to be a link between the polarisation of attitudes on sexual matters, such that the previously more conservative regions and groups have joined the (highly educated) white population in London in their support for LGBT rights in sharp contrast to (some groups of) immigrants and minorities. Whilst on an issue such as law and order, where Muslims hold quite conservative views, there is no evidence of liberalisation amongst the white population that have also held traditionally conservative views. However, we have only focused on one potential mechanism through which this strategic effect could be manifested. Therefore, further evidence on this issue would help to provide a deeper understanding of the relevant relationships.

\section{References}

Abbas, T. (2007). Muslim minorities in Britain: Integration, multiculturalism and radicalism in the post-7/7 period. Journal of Intercultural Studies, 28(3), 287-300.

Akkerman, T. (2005). Anti-immigration parties and the defence of liberal values: The exceptional case of the List Pim Fortuyn. Journal of Political Ideologies, 10, 337-354.

Allport, G.W. (1954). The Nature of Prejudice. New York: Anchor. 
Almeida, D. (2017). Exclusionary secularism: The Front National and the reinvention of laïcité. Modern \& Contemporary France, 25, 249-263.

Andersen, R. and Fetner, T. (2008). Cohort differences in tolerance of homosexuality: Attitudinal change in Canada and the United States, 1981-2000, Public Opinion Quarterly, 72(2), 311-330.

Betz, H. G. (2016). Against the 'green totalitarianism': Anti-Islamic nativism in contemporary radical right-wing populism in Western Europe. In C. Liang (ed) Europe for the Europeans. London: Routledge.

Blanchflower, D. (1991). Fear, unemployment and pay flexibility. Economic Journal, 101(406), 483-496.

Blinder, A. S. (1973). Wage discrimination: Reduced form and structural estimates. Journal of Human Resources, 8, 436-455.

Brittain, C. C. and McKinnon, A. (2011). Homosexuality and the construction of "Anglican orthodoxy": The symbolic politics of the Anglican communion. Sociology of Religion, 72(3), 351-373.

Cameron, S., Collins, A., Drinkwater, S., Hickson, F., Reid, D., Roberts, J., Stephens, M. and Weatherburn, P. (2009). Surveys and data sources on gay men's lifestyles and socio-sexual behavior: Some key concerns and issues. Sexuality \& Culture, 13(3), $135-151$.

Chan, T. W. and Goldthorpe, J. H. (2007). Class and status: The conceptual distinction and its empirical relevance. American Sociological Review, 72(4), 512532. 
Clarke, H. D., Goodwin, M. and Whiteley, P. (2017). Why Britain voted for Brexit: An individual-level analysis of the 2016 referendum vote. Parliamentary Affairs, 70(3), 439-464.

Collins, A. and Drinkwater, S. (2017). Fifty shades of gay: Social and technological change, urban deconcentration and niche enterprise. Urban Studies, 54(3), 765-785.

Eatwell, R. and Goodwin, M. (2018). National Populism: The Revolt Against Liberal Democracy. London: Pelican.

English, P. (2019). Visibly restricted: Public opinion and the representation of immigrant origin communities across Great Britain. Ethnic and Racial Studies, 42(9), $1437-1455$.

Fortin, N., Lemieux, T. and Firpo, S. (2011). Decomposition methods in economics. In D. Card and O. Ashenfelter (eds) Handbook of Labor Economics, Volume 4. Amsterdam: Elsevier.

Fielding, D. (2018). Traditions of tolerance: The long-run persistence of regional variation in attitudes towards English immigrants. British Journal of Political Science, 48(1), 167-188.

Georgiadis, A. and Manning, A. (2012). Spend it like Beckham? Inequality and redistribution in the UK, 1983-2004. Public Choice, 151(3-4), 537-563.

Giani, M. and Meon, PG. (forthcoming). Global racist contagion following Donald Trump's election. British Journal of Political Science

Glaeser, E. L. (2005). The political economy of hatred. Quarterly Journal of Economics, 120(1), 45-86.

Goodwin, M. and Milazzo, C. (2017). Taking back control? Investigating the role of immigration in the 2016 vote for Brexit. British Journal of Politics and International Relations, 19(3), 450-464. 
Gorinas, C. (2014). Ethnic identity, majority norms, and the native-immigrant employment gap. Journal of Population Economics, 27(1), 225-250.

Grasso, M. T., Farrall, S., Gray, E., Hay, C. and Jennings, W. (2019). Thatcher's children, Blair's babies, political socialization and trickle-down value change: An age, period and cohort analysis. British Journal of Political Science, 49(1), 17-36.

Jann, B. (2008). The Blinder-Oaxaca decomposition for linear regression models. Stata Journal, 8(4), 453-479.

Jennings, C. and Ralph-Morrow E. (2020). Selective Tolerance and the Radical Right. Rationality and Society, 32(2), 144-167.

Jepsen, C. and Jepsen, L. K. (2009). Does home ownership vary by sexual orientation? Regional Science and Urban Economics, 39(3), 307-315.

Jürges, H. (2007). True health vs response styles: Exploring cross-country differences in self-reported health. Health Economics, 16(2), 163-178.

Loftus, J. (2001). America's liberalization in attitudes toward homosexuality, 1973 to 1998. American Sociological Review, 66(5), 762-782.

Meadowcroft, J. and Morrow, E. (2017). Violence, self-worth, solidarity and stigma: How a dissident, radical right group solves the collective action problem. Political Studies, 65, 373-390.

Modood, T., 2005. Muslim Britain: Communities Under Pressure. London: Zed Books.

Narkowicz, K. and Pędziwiatr, K. (2017). Saving and fearing Muslim women in 'post-communist' Poland: troubling Catholic and secular Islamophobia. Gender, Place \& Culture, 24(2), 288-299. 
Oaxaca, R. (1973), Male-female wage differentials in urban labor markets. International Economic Review, 14, 693-709.

Oaxaca, R. L. and Ransom, M. R. (1994). On discrimination and the decomposition of wage differentials, Journal of Econometrics, 61, 5-21.

Poynting, S. and Mason, V. (2006). Tolerance, freedom, justice and peace? Britain, Australia and anti-Muslim racism since 11 September 2001. Journal of Intercultural Studies, 27(4), 365-391.

Ragazzi, F. (2016). Suspect community or suspect category? The impact of counterterrorism as 'policed multiculturalism'. Journal of Ethnic and Migration Studies, 42(5), 724-741.

Ueffing, P., Rowe, F. and Mulder, C. H. (2015). Differences in attitudes towards immigration between Australia and Germany: The role of immigration policy. Comparative Population Studies, 40(4), 438-464.

White, N. (2018), Local Area Migration Indicators, UK, Office for National Statistics, Available at:

https://www.ons.gov.uk/peoplepopulationandcommunity/populationandmigration/mig rationwithintheuk/datasets/localareamigrationindicatorsunitedkingdom

[Accessed: $3^{\text {rd }}$ April 2020]. 
Table 1

Attitudes Towards Homosexual Relations by Time Period

\begin{tabular}{lcccc}
\hline \hline & $\mathbf{1 9 8 3 - 8 9}$ & $\mathbf{1 9 9 0 - 9 9}$ & $\mathbf{2 0 0 0 - 9}$ & $\mathbf{2 0 1 0 - 1 5}$ \\
\hline \% Stating Always Wrong (5) & 56.18 & 47.75 & 31.84 & 17.58 \\
\% Stating Mostly Wrong (4) & 11.55 & 11.44 & 9.37 & 7.86 \\
\% Stating Sometimes Wrong (3) & 7.75 & 8.54 & 8.58 & 7.31 \\
\% Stating Rarely Wrong (2) & 3.28 & 5.91 & 7.58 & 8.55 \\
\% Stating Not Wrong at All (1) & 14.07 & 19.97 & 35.67 & 52.62 \\
\% Stating Depends/Varies & 5.48 & 4.22 & 4.24 & 3.74 \\
\% Stating Don't Know & 0.59 & 1.38 & 2.29 & 1.87 \\
\% Refusing to Answer & 1.10 & 0.79 & 0.44 & 0.48 \\
\hline Number of Observations (N): All & 8,190 & 6,180 & 9,790 & 6,526 \\
\hline Mean Attitudes (1-5) & \multicolumn{3}{c}{} \\
\hline All Respondents & 4.00 & 3.65 & 2.94 & 2.25 \\
\hline Ethnicity & & & \\
Whites & 3.98 & 3.64 & 2.89 & 2.15 \\
Ethnic Minority & 4.36 & 4.01 & 3.55 & 3.36 \\
Regions & & & & \\
Scotland & 4.15 & 3.65 & 2.86 & 2.16 \\
Wales & 4.32 & 3.94 & 3.07 & 2.27 \\
North & 3.99 & 3.72 & 2.99 & 2.12 \\
Midlands & 4.11 & 3.79 & 3.05 & 2.36 \\
South/East & 3.94 & 3.54 & 2.85 & 2.23 \\
London & 3.66 & 3.49 & 2.91 & 2.49 \\
\hline \hline
\end{tabular}

Notes:

1. Statistics in table are based on unweighted data.

2. Number of observations (All) is based on individuals giving a response to the question on view of homosexual relations.

3. Those who didn't answer the question or said Don't Know/Can't Say have been removed from the mean attitudes.

4. A higher mean value indicates less tolerant attitudes. 
Table 2

Ordered Probit Estimates of Attitudes Towards Homosexual Relations: Key Explanatory Variables

\begin{tabular}{|c|c|c|c|c|c|c|c|c|}
\hline & \multicolumn{2}{|c|}{ (1) } & \multicolumn{2}{|c|}{ (2) } & \multicolumn{2}{|c|}{ (3) } & \multicolumn{2}{|c|}{ (4) } \\
\hline & Coef. & S. E. & Coef. & S. E. & Coef. & S. E. & Coef. & S. E. \\
\hline $1990 \mathrm{~s}$ & $-0.240^{* * *}$ & 0.020 & $-0.192^{* * *}$ & 0.021 & $-0.241^{* * *}$ & 0.021 & $-0.224^{* * *}$ & 0.021 \\
\hline $2000 \mathrm{~s}$ & $-0.715^{* * *}$ & 0.018 & $-0.644^{* * *}$ & 0.019 & $-0.768^{* * *}$ & 0.020 & $-0.748^{* * *}$ & 0.020 \\
\hline $2010 \mathrm{~s}$ & $-1.188^{* * *}$ & 0.020 & $-1.084^{* * *}$ & 0.021 & $-1.322^{* * *}$ & 0.023 & $-1.295^{* * *}$ & 0.024 \\
\hline Scotland & $0.075^{* *}$ & 0.032 & $0.124^{* * *}$ & 0.033 & $0.134^{* * *}$ & 0.034 & $0.065^{*}$ & 0.035 \\
\hline Wales & $0.226^{* * *}$ & 0.037 & $0.274^{* * *}$ & 0.038 & $0.245^{* * *}$ & 0.039 & $0.233^{* * *}$ & 0.039 \\
\hline North & $0.069^{* * *}$ & 0.026 & $0.076^{* * *}$ & 0.027 & $0.089^{* * *}$ & 0.028 & $0.077^{* * *}$ & 0.028 \\
\hline Midlands & $0.153^{* * *}$ & 0.028 & $0.151^{* * *}$ & 0.029 & $0.162^{* * *}$ & 0.030 & $0.164^{* * *}$ & 0.029 \\
\hline South/East & 0.017 & 0.025 & $0.091^{* * *}$ & 0.026 & $0.055^{* *}$ & 0.027 & $0.070^{* *}$ & 0.027 \\
\hline Female & $-0.249^{* * *}$ & 0.014 & $-0.263^{* * *}$ & 0.014 & $-0.281^{* * *}$ & 0.014 & $-0.367^{* * *}$ & 0.016 \\
\hline Ethnic Minority & - & - & $0.802^{* * *}$ & 0.035 & $0.924^{* * *}$ & 0.037 & $0.581^{* * *}$ & 0.044 \\
\hline Left FT Ed. at 16 & - & - & $-0.534^{* * *}$ & 0.018 & $-0.190^{* * *}$ & 0.020 & $-0.174^{* * *}$ & 0.020 \\
\hline Left FT Ed. at 17 & - & - & $-0.617^{* * *}$ & 0.027 & $-0.326^{* * *}$ & 0.028 & $-0.325^{* * *}$ & 0.028 \\
\hline Left FT Ed. at 18 & - & - & $-0.755^{* * *}$ & 0.026 & $-0.402^{* * *}$ & 0.028 & $-0.415^{* * *}$ & 0.028 \\
\hline Left FT Ed. at 19 or over & - & - & $-0.889^{* * *}$ & 0.021 & $-0.539^{* * *}$ & 0.023 & $-0.556^{* * *}$ & 0.023 \\
\hline Still in FT Ed. & & & $-1.157^{* * *}$ & 0.050 & $-0.624^{* * *}$ & 0.057 & $-0.655^{* * *}$ & 0.062 \\
\hline Controls for Age & \multicolumn{2}{|c|}{ No } & \multicolumn{2}{|c|}{ No } & \multicolumn{2}{|c|}{ Yes } & \multicolumn{2}{|c|}{ Yes } \\
\hline Controls for Marital Stat. & \multicolumn{2}{|c|}{ No } & \multicolumn{2}{|c|}{ No } & \multicolumn{2}{|c|}{ Yes } & \multicolumn{2}{|c|}{ Yes } \\
\hline Controls for Relig. Group & \multicolumn{2}{|c|}{ No } & \multicolumn{2}{|c|}{ No } & \multicolumn{2}{|c|}{ No } & \multicolumn{2}{|c|}{ Yes } \\
\hline Controls for Econ. Activity & \multicolumn{2}{|c|}{ No } & \multicolumn{2}{|c|}{ No } & \multicolumn{2}{|c|}{ No } & \multicolumn{2}{|c|}{ Yes } \\
\hline Pseudo R-squared & \multicolumn{2}{|c|}{0.057} & \multicolumn{2}{|c|}{0.093} & \multicolumn{2}{|c|}{0.125} & \multicolumn{2}{|c|}{0.138} \\
\hline $\mathrm{N}$ & \multicolumn{2}{|c|}{28,625} & \multicolumn{2}{|c|}{28,490} & \multicolumn{2}{|c|}{28,423} & \multicolumn{2}{|c|}{28,370} \\
\hline
\end{tabular}

Notes:

1. Reference categories are 1980s, London, Male and Left Full-Time Education before the age of 16 .

2. Robust standard errors are reported.

3. ${ }^{* * *} \mathrm{p}<0.001,{ }^{* *} \mathrm{p}<0.05$ and ${ }^{*} \mathrm{p}<0.1$. 
Table 4

Ordered Probit Estimates of Decades, Education and Interaction Terms for Attitudinal Variables for Whites

\begin{tabular}{|c|c|c|c|c|c|c|}
\hline & \multicolumn{2}{|c|}{$\begin{array}{c}\text { Homosexual } \\
\text { Relations }\end{array}$} & \multicolumn{2}{|c|}{$\begin{array}{c}\text { Pre-Marital } \\
\text { Sex }\end{array}$} & \multicolumn{2}{|c|}{$\begin{array}{c}\text { Stiffer } \\
\text { Sentences }\end{array}$} \\
\hline & Coef. & S. E. & Coef. & S. E. & Coef. & S. E. \\
\hline $1990-99$ & $-0.242^{* * *}$ & 0.053 & $-0.278^{* * *}$ & 0.053 & 0.054 & 0.058 \\
\hline $2000-09$ & $-0.758^{* * *}$ & 0.046 & $-0.693^{* * *}$ & 0.047 & $0.186^{* * *}$ & 0.054 \\
\hline $2010-15$ & $-1.274^{* * *}$ & 0.050 & $-1.048^{* * *}$ & 0.052 & $0.129^{* *}$ & 0.055 \\
\hline Low Education & $0.538^{* * *}$ & 0.040 & $-0.127^{* * *}$ & 0.038 & $0.751^{* * *}$ & 0.056 \\
\hline Medium Education & $0.223^{* * *}$ & 0.052 & -0.044 & 0.048 & $0.424^{* * *}$ & 0.070 \\
\hline Low Education * 1990s & -0.002 & 0.059 & -0.038 & 0.058 & -0.072 & 0.063 \\
\hline Low Education * 2000s & -0.035 & 0.052 & 0.020 & 0.052 & -0.090 & 0.060 \\
\hline Low Education * 2010s & $-0.160^{* * *}$ & 0.056 & 0.028 & 0.058 & -0.091 & 0.061 \\
\hline Medium Education * 1990 s & 0.031 & 0.075 & -0.114 & 0.074 & -0.042 & 0.079 \\
\hline Medium Education * 2000s & -0.008 & 0.066 & -0.056 & 0.066 & -0.028 & 0.075 \\
\hline Medium Education * 2010s & -0.038 & 0.071 & -0.072 & 0.074 & 0.021 & 0.077 \\
\hline R-squared & \multicolumn{2}{|c|}{0.139} & \multicolumn{2}{|c|}{0.131} & \multicolumn{2}{|c|}{0.031} \\
\hline $\mathrm{N}$ & \multicolumn{2}{|c|}{26,778} & \multicolumn{2}{|c|}{27,333} & \multicolumn{2}{|c|}{41,941} \\
\hline
\end{tabular}

Notes:

1. Low Education relates to respondents leaving education at 16 or earlier, Medium Education to those leaving aged 17 and 18 and High Education to those leaving at 19 or over or are still in FT education.

2. Reference categories are 1980s and High Education.

3. Models also include controls for gender, age, marital status, religion, economic activity and region.

4. Robust standard errors are reported.

5. ${ }^{* * *} \mathrm{p}<0.001,{ }^{* *} \mathrm{p}<0.05$ and $^{*} \mathrm{p}<0.1$. 
Table 5

\section{Ordered Probit Estimates of Time Trend, Highest Qualification and Interaction Terms for Attitudinal Variables for Whites: 1997-2015}

\begin{tabular}{|c|c|c|c|c|c|c|}
\hline & \multicolumn{2}{|c|}{$\begin{array}{c}\text { Homosexual } \\
\text { Relations }\end{array}$} & \multicolumn{2}{|c|}{$\begin{array}{c}\text { Pre-Marital } \\
\text { Sex }\end{array}$} & \multicolumn{2}{|c|}{$\begin{array}{c}\text { Stiffer } \\
\text { Sentences }\end{array}$} \\
\hline & Coef. & S. E. & Coef. & S. E. & Coef. & S. E. \\
\hline Time Trend & $-0.053^{* * *}$ & 0.004 & $-0.048^{* * *}$ & 0.004 & 0.000 & 0.003 \\
\hline Other Higher Education & $0.376^{* * * *}$ & 0.133 & $-0.315^{* *}$ & 0.139 & $0.431^{* * *}$ & 0.093 \\
\hline A Levels or Equivalent & $0.543^{* * *}$ & 0.132 & $-0.515^{* * *}$ & 0.146 & $0.483^{* * *}$ & 0.094 \\
\hline GCSEs or equivalent & $0.641^{* * *}$ & 0.121 & $-0.501^{* * *}$ & 0.131 & $0.578^{* * *}$ & 0.086 \\
\hline O Levels or Equivalent & $0.875^{* * *}$ & 0.153 & $-0.432^{* * *}$ & 0.165 & $0.765^{* * *}$ & 0.107 \\
\hline Foreign or Other Qualifications & 0.117 & 0.326 & -0.056 & 0.350 & $0.603^{* * *}$ & 0.242 \\
\hline No Qualifications & $0.936^{* * *}$ & 0.116 & $-0.251^{* *}$ & 0.121 & $0.916^{* * *}$ & 0.083 \\
\hline Trend*Other Higher Education & -0.003 & 0.006 & $0.012^{* *}$ & 0.006 & 0.003 & 0.004 \\
\hline Trend*A Levels or Equivalent & $-0.010^{*}$ & 0.005 & $0.019^{* * *}$ & 0.006 & 0.004 & 0.004 \\
\hline Trend*GCSEs or equivalent & $-0.009^{*}$ & 0.005 & $0.016^{* * *}$ & 0.005 & 0.006 & 0.003 \\
\hline Trend*CSE or Equivalent & $-0.014^{* *}$ & 0.006 & $0.014^{* *}$ & 0.007 & 0.001 & 0.004 \\
\hline Trend*Foreign or Other Qualifications & 0.018 & 0.013 & 0.002 & 0.014 & 0.000 & 0.010 \\
\hline Trend*No Qualifications & $-0.010^{* *}$ & 0.005 & $0.010^{* *}$ & 0.005 & 0.001 & 0.003 \\
\hline R-squared & \multicolumn{2}{|c|}{0.131} & \multicolumn{2}{|c|}{0.123} & \multicolumn{2}{|c|}{0.039} \\
\hline $\mathrm{N}$ & \multicolumn{2}{|c|}{16,580} & \multicolumn{2}{|c|}{16,932} & \multicolumn{2}{|c|}{33,659} \\
\hline
\end{tabular}

Notes:

1. Reference category for qualifications is Degree.

2. Models also include controls for gender, age, marital status, religion, economic activity and region.

3. Robust standard errors are reported.

4. ${ }^{* * *} \mathrm{p}<0.001,{ }^{* *} \mathrm{p}<0.05$ and ${ }^{*} \mathrm{p}<0.1$. 
Table 6

Change in Mean Attitudes Towards Homosexual Relations by Educational Group

\begin{tabular}{|c|c|c|c|c|c|c|c|c|}
\hline \multirow{2}{*}{$\begin{array}{l}\text { Age left FT } \\
\text { Education }\end{array}$} & \multicolumn{2}{|c|}{ Period 1-2 } & \multicolumn{2}{|c|}{ Period 2-3 } & \multicolumn{2}{|c|}{ Period 3-4 } & \multicolumn{2}{|c|}{ Overall } \\
\hline & Change & $\%$ & Change & $\%$ & Change & $\%$ & Change & $\%$ \\
\hline 15 or under & -0.16 & -4 & -0.54 & -13 & -0.68 & -19 & -1.39 & -32 \\
\hline 16 & -0.31 & -8 & -0.69 & -20 & -0.68 & -24 & -1.68 & -44 \\
\hline 17 & -0.34 & -9 & -0.69 & -20 & -0.62 & -23 & -1.65 & -44 \\
\hline 18 & -0.35 & -10 & -0.66 & -21 & -0.51 & -20 & -1.52 & -44 \\
\hline 19 or over & -0.38 & -12 & -0.58 & -20 & -0.42 & -18 & -1.38 & -42 \\
\hline Still in FT Ed. & -0.37 & -12 & -0.53 & -20 & -0.34 & -16 & -1.25 & -42 \\
\hline All & -0.34 & -9 & -0.72 & -20 & -0.69 & -24 & -1.75 & -44 \\
\hline
\end{tabular}




\section{Appendix}

Table A1

Descriptive Statistics for Explanatory Variables and Full Set of Estimates for Attitudes Towards Homosexual Relations

\begin{tabular}{|c|c|c|c|c|c|c|}
\hline & \multicolumn{2}{|c|}{ Descriptives } & \multicolumn{2}{|c|}{ Ordered Probit } & \multicolumn{2}{|c|}{ OLS } \\
\hline & Mean & S. D. & Coef. & S. E. & Coef. & S. E. \\
\hline $1990 \mathrm{~s}$ & 0.202 & 0.402 & $-0.224^{* * *}$ & 0.021 & $-0.281^{* * *}$ & 0.026 \\
\hline $2000 \mathrm{~s}$ & 0.318 & 0.466 & $-0.748^{* * *}$ & 0.020 & $-0.964^{* * *}$ & 0.024 \\
\hline $2010 \mathrm{~s}$ & 0.215 & 0.410 & $-1.295^{* * *}$ & 0.024 & $-1.621^{* * *}$ & 0.027 \\
\hline Scotland & 0.093 & 0.290 & $0.065^{*}$ & 0.035 & 0.059 & 0.042 \\
\hline Wales & 0.055 & 0.228 & $0.233^{* * *}$ & 0.039 & $0.259^{* * *}$ & 0.046 \\
\hline North & 0.263 & 0.440 & $0.077^{* * *}$ & 0.028 & $0.074^{* *}$ & 0.034 \\
\hline Midlands & 0.171 & 0.377 & $0.164^{* * *}$ & 0.029 & $0.184^{* * *}$ & 0.036 \\
\hline South/East & 0.318 & 0.466 & $0.070^{* *}$ & 0.027 & $0.067^{* *}$ & 0.033 \\
\hline Female & 0.550 & 0.498 & $-0.367^{* * *}$ & 0.016 & $-0.448^{* * *}$ & 0.019 \\
\hline Ethnic Minority & 0.056 & 0.230 & $0.581^{* * *}$ & 0.044 & $0.707^{* * *}$ & 0.054 \\
\hline Left FT Education at 16 & 0.268 & 0.443 & $-0.174^{* * *}$ & 0.020 & $-0.216^{* * *}$ & 0.025 \\
\hline Left FT Education at 17 & 0.079 & 0.269 & $-0.325^{* * *}$ & 0.028 & $-0.412^{* * *}$ & 0.036 \\
\hline Left FT Education at 18 & 0.086 & 0.281 & $-0.415^{* * *}$ & 0.028 & $-0.544^{* * *}$ & 0.036 \\
\hline Left FT Ed. at 19 or over & 0.174 & 0.379 & $-0.556^{* * *}$ & 0.023 & $-0.719^{* * *}$ & 0.029 \\
\hline Still in FT Education & 0.019 & 0.138 & $-0.655^{* * *}$ & 0.062 & $-0.833^{* * *}$ & 0.075 \\
\hline Age & 48.304 & 18.122 & $-0.021^{* * *}$ & 0.003 & $-0.024^{* * *}$ & 0.003 \\
\hline Age Squared/100 & 26.617 & 18.615 & $0.038^{* * *}$ & 0.000 & $0.043^{* * *}$ & 0.000 \\
\hline Cohabiting & 0.065 & 0.247 & $-0.216^{* * *}$ & 0.031 & $-0.302^{* * *}$ & 0.038 \\
\hline Divorced/Separated & 0.105 & 0.307 & $-0.163^{* * *}$ & 0.024 & $-0.222^{* * *}$ & 0.031 \\
\hline Widowed & 0.110 & 0.313 & -0.016 & 0.029 & -0.012 & 0.032 \\
\hline Single & 0.193 & 0.394 & $-0.079^{* * *}$ & 0.023 & $-0.109^{* * *}$ & 0.028 \\
\hline Catholic & 0.095 & 0.294 & $0.352^{* * *}$ & 0.026 & $0.444^{* * *}$ & 0.032 \\
\hline Church of England & 0.300 & 0.458 & $0.291^{* * *}$ & 0.018 & $0.386^{* * *}$ & 0.023 \\
\hline Other Christian & 0.167 & 0.373 & $0.492^{* * *}$ & 0.022 & $0.612^{* * *}$ & 0.027 \\
\hline Hindu/Sikh & 0.010 & 0.100 & $0.458^{* * *}$ & 0.083 & $0.580^{* * *}$ & 0.104 \\
\hline Muslim & 0.014 & 0.118 & $1.503^{* * *}$ & 0.084 & $1.662^{* * *}$ & 0.078 \\
\hline Other Religion & 0.011 & 0.102 & 0.044 & 0.075 & 0.065 & 0.092 \\
\hline Unemployed & 0.055 & 0.228 & $0.062^{*}$ & 0.033 & $0.073^{*}$ & 0.041 \\
\hline Looking after home & 0.124 & 0.330 & $0.202^{* * *}$ & 0.024 & $0.251^{* * *}$ & 0.030 \\
\hline Retired & 0.222 & 0.416 & $0.053^{*}$ & 0.028 & $0.108^{* * *}$ & 0.032 \\
\hline Other activity & 0.074 & 0.261 & 0.030 & 0.033 & 0.031 & 0.040 \\
\hline Constant & & & & & 4.031 & 0.088 \\
\hline R-Squared/Pseudo R-sq & & & & & 0.32 & \\
\hline
\end{tabular}

Cut 1 
Cut 2

$-1.003$

Cut 3

$-0.709$

Cut 4

$-0.357$

Pseudo R-squared

0.138

$\mathrm{N}$

Notes:

1. Data are unweighted.

2. Means and standard deviations relate to the sample used in the regressions reported in Table 2.

3. Reference categories are 1980s, Lives in London, White, Male, Left Full-Time Education before Age 16, Married, No Religion and Employed.

4. Robust standard errors are reported.

5. ${ }^{* * *} \mathrm{p}<0.001,{ }^{* *} \mathrm{p}<0.05$ and ${ }^{*} \mathrm{p}<0.1$. 
